\title{
Contingency Fit, Institutional Fit, and Firm Performance: A Metafit Approach to Organization-Environment Relationships
}

\author{
Henk W. Volberda \\ Department of Strategic Management and Entrepreneurship, Rotterdam School of Management, Erasmus University, \\ and INSCOPE: Research for Innovation, 3000 DR Rotterdam, The Netherlands, hvolberda@rsm.nl \\ Niels van der Weerdt \\ Department of Strategic Management and Entrepreneurship, Rotterdam School of Management, Erasmus University, \\ 3000 DR Rotterdam, The Netherlands, nweerdt@rsm.nl \\ Ernst Verwaal \\ Queen's University Management School, Queen's University Belfast, BT7 1NN Belfast, \\ United Kingdom, e.verwaal@qub.ac.uk \\ Marten Stienstra \\ Department of Strategic Management and Entrepreneurship, Rotterdam School of Management, Erasmus University, \\ 3000 DR Rotterdam, The Netherlands, msteinstra@rsm.nl \\ Antonio J. Verdu \\ Finance and Economics Department, Miguel Hernandez University, 03202 Elche, Spain, ajverdu@umh.es
}

\begin{abstract}
In this paper, we attempt to reconcile contingency and institutional fit approaches concerning the organization-environment relationship. Whereas prior scholarly research has examined both theories and compared their impacts on organizational fit and performance, we lay the groundwork for a metafit approach by investigating how contingency and institutional fit interact to influence firm performance. We test our theoretical framework using a data set of 3,259 respondents from 1,904 companies, examining task environmental demands and institutional demands on organizational design across a broad range of industries and firm size classes. Our results show that contingency and institutional fit provide complementary and interdependent explanations of firm performance. Importantly, our findings indicate that for firms under conditions of "quasi fit" rather than perfect contingency fit or optimal institutional fit, improvements in contingency and/or institutional fit will result in better performance. However, firms with high contingency fit are less vulnerable to deviation from institutional fit in the formation of firm performance, whereas firms with perfect institutional fit will slightly decrease their performance when they strive to achieve contingency fit.
\end{abstract}

Key words: contingency fit; institutional fit; metafit; quasi fit; organization design; task environment; environmental turbulence; organizational effectiveness; institutional environment; external legitimacy; organizational field; firm performance

History: Published online in Articles in Advance September 28, 2011.

\section{Introduction}

What criteria do successful firms use with regard to appropriate strategies and their organizational design? Do they strive to continuously adjust specific organization variables to specific elements in the task environment, or do they conform to the institutional pressures of the business environment? Scholarly research streams in the strategic management literature have acknowledged that the fit of the organization with environmental demands is an important precursor of high firm performance (cf. Burton and Obel 2004, Burton et al. 2008). According to contingency theory, high performance results from a fit between the organization and its environmental contingencies (Donaldson 2001, Drazin and Van de Ven 1985, Venkatraman 1989). Institutional theory is also primarily concerned with the organization's relationship with the environment, but explains firm performance as a consequence of legitimacy and support that come externally (DiMaggio and Powell 1983, Scott 2001, Zucker 1987), leading to the notion of institutional fit (Kondra and Hinings 1998), or congruence of the organization's characteristics with the institutional template (Greenwood and Hinings 1996). The implications of these two fit approaches may lead to both complementary and conflicting prescriptions for organizational design (Donaldson 2008b). Integrating these perspectives is therefore important for theory and practice because neither perspective can, on its own, explain 
the success of firm behavior and the firm's relationship with the environment.

According to contingency theory, managers carefully analyze the firm's task environment, taking into account the internal characteristics of the firm, and adapt their practices accordingly. On the other hand, according to institutional theory, the environment exerts strong pressures for institutional fit or adoption of "conformanceenhancing templates" (Heugens and Lander 2009, p. 64). Previous scholarly research (Carroll 1993, Child et al. 2003, Greening and Gray 1994, Gupta et al. 1994, Kraatz and Zajac 1996) has examined both theories and compared their impacts on organizational change and performance. However, these studies did not investigate what impact conceptual and empirical linkages between the two approaches may have on firm performance. If such linkages exist and are substantial, a single-lens approach to fit may produce incomplete theoretical predictions and conclusions. In this study, we address this underdeveloped area of research by explicitly focusing on how contingency fit and institutional fit interact to influence firm performance.

Contingency theories include a variety of approaches that focus on either the effectiveness of fit across a variety of firms or the adaptation processes by which individual firms achieve fit with their task environments. The first approach requires a comparison across firms that differ in organizational and task environmental variables, whereas the latter requires a longitudinal study of organizational adaptation processes. In this paper, we focus on the first approach; i.e., the performance implications of contingency fit across a variety of firms (Drazin and Van de Ven 1985, Venkatraman 1989). To investigate the simultaneous impact of contingency fit and institutional fit, we study the performance implications of institutional fit across the same set of firms. Although institutional theory is used primarily to describe organizational processes, this paper responds to institutional theorists who have mentioned the possibility of applying a cross-sectional research design (see DiMaggio and Powell 1983). Furthermore, to define the notion of fit explicitly with respect to a specific outcome over a specific time period (Donaldson 2001), we studied fit in relation to short-term organizational performance.

The rest of this paper proceeds as follows. First, we define the notion of fit and specify and test hypotheses regarding various notions of fit. We formulate hypotheses with respect to a contingency-fit-based model, which captures factors related to specific requirements of the task environment, and to an institutional-fit-based model, which captures pressures for conformity to the institutional environment. Furthermore, we develop hypotheses on the combined effects of these models. Since we are interested in the short-term performance implications of fit, to test our hypotheses we use a large-scale crosssectional sample of firms across a wide range of industries and firm size classes. Next, we present the results, finding that contingency and institutional fit are complementary and interrelated explanations of firm performance, and show that the combination of both theories produces superior insights into the relationship between fit and firm performance. In the final section, we discuss the implications of these findings for management and scholarly work.

\section{Theory and Hypotheses}

\section{The Notion of Fit}

The concept of fit has been explored widely in organization and strategy literatures and covers much of the descriptive and prescriptive research in this arena. Fit is a polyvalent concept, rooted in contingency theory and population ecology (Van de Ven 1979), and subsequently developed in the fields of organization theory (Drazin and Van de Ven 1985, Van de Ven and Drazin 1985) and strategic management (Venkatraman 1989). The concept of fit has been used by both organization theorists and strategic management scholars as a key predictor of firm performance. Although fit originated in contingency theory, institutional theorists have also taken up the concept (e.g., Kondra and Hinings 1998). Furthermore, Donaldson (2008b) demonstrated that knowledge of how organizations attain external legitimacy and support leads to valuable prescriptions for organizational design that often conflict with contingency theory. Building on Donaldson's (2008b) notion that organizations need to maximize both internal organizational effectiveness and external legitimacy support, our study analyzes fit implications for performance across both contingency theory and institutional theory.

The notion of fit has been extensively defined in the literature (Van de Ven and Drazin 1985, Venkatraman 1989, Parker and Witteloostuijn 2010). In general, there are two main operational definitions of fit in the literature: interaction and congruence (Pennings 1987). However, as suggested by Donaldson (2001, pp. 189-191), a multiplicative interaction fails to capture the relationship between contingency fit and performance. Therefore, in this study we use the concept of fit as congruence, which holds that high performance occurs when organizational response variables match environmental variables. More specifically, we link three organizational design variables (technology, structure, and culture) with both task environmental demands (i.e., contingency fit) and institutional demands (i.e., institutional fit) to investigate how both types of fit separately and jointly explain organizational performance.

\section{Contingency Theory, Contingency Fit, and Firm Performance}

Contingency theory is a midrange theory that involves identifying and matching context settings with organizational settings (Hambrick 1983). Since the 1960s, a 
considerable volume of research has been conducted using contingency theory as the principal framework, relating the task environment to organizational characteristics (Burns and Stalker 1961, Emery and Trist 1965, Lawrence and Lorsch 1967, Woodward 1965) or to strategic management (Hambrick 1983, Hofer 1975, Porter 1980).

Contingency theory suggests that the appropriate organizational structure and management style depend on a set of "contingency" factors (Tosi and Slocum 1984). According to contingency theory, there is no best way of organizing; the appropriate form depends on the nature of the firm's task environment (Donaldson 2001). Task environmental conditions are considered a direct source of variation in organizational forms. Some authors suggest appropriate forms based on the speed of environmental change (Burns and Stalker 1961), rate of technological innovation (Woodward 1965), or level of uncertainty (Lawrence and Lorsch 1967). Neocontingency theorists (Hrebiniak and Joyce 1985, Zajac et al. 2000) add a dynamic perspective of fit, in which adaptation is a dynamic process that is both managerially and environmentally inspired. Donaldson (2001) proposes the notion of quasi fit as a key to high performance, because the permanent disequilibrium triggers a constant search for strategic and structural change.

Contingency fit was examined in research by Roth and Morrison (1992) on environment-strategy coalignment and more recently in research by Hitt et al. (2001) on resource strategy. Priem (1994) explained high performance as being a consequence of strategystructure-environment matches that were based on executive judgments. Burton et al. (2002, 2003) used contingency fit to describe the internal consistency of multiple contingencies (e.g., size, climate, strategy, environment, leadership preferences) and multiple structural characteristics. Zajac et al. (2000) used contingency theory in a multicontingent environment-strategy fit defined as strategic fit. Others supported the fit hypothesis using the alignment of a few variables such as organization structure and dimensions of knowledge (Birkinshaw et al. 2002). Venkatraman and Prescott (1990) referred to contingency fit when a few characteristics of contextual variables are coaligned with those of other organizational variables (e.g., technology, structure, culture, strategy).

According to Zeithaml et al. (1988) and Tosi and Slocum (1984), contingency theory building involves three types of variables (contingency, response, and effectiveness variables) and congruency or a notion of fit. Contingency variables relate to environmental context, and response variables to organizational structure or managerial actions. Effectiveness can be considered as performance in a narrow sense (Lawrence and Lorsch 1967). The essential premise of contingency theory is that effectiveness (high performance) can be achieved in more than one way. High performance is a consequence of coalignment between a limited number of organizational and environmental factors (Donaldson 1987, Tosi and Slocum 1984).

The fit line is central to the notion of fit as congruence, and misfit is defined as deviation from that fit line. The fit line is considered to be a line of isoperformance (Van de Ven and Drazin 1985), meaning that for each value of the contingency variables, there is a value for the organizational variables that constitutes fit and produces the highest performance for that value of the contingency. All fits are equally good and better than misfits. The identification of a misfit involves a two-step procedure. The first step involves approximating the optimal fit line between a contingency and a response variable. In the second step, deviation from the optimal fit line is calculated to represent misfit, using the following equation:

$$
A=X-(c * Z),
$$

where $A$ is the contingency misfit, $X$ is the organizational response variable, $c$ is the optimal fit line coefficient, and $Z$ is the contingency variable. In case of multiple contingencies, the separate misfits can be combined in an additive model to arrive at a multiple contingencies fit (Donaldson 2001, p. 197-198).

According to the congruence definition of contingency fit, the impact of organizational response variables on firm performance depends on environmental characteristics according to the following equation:

$$
Y=f\left(X_{1-3}, Z, \operatorname{abs}\left(X_{1-3}-X_{Z}\right)\right),
$$

where $Y$ is performance, $X_{1-3}$ are organizational response variables (technology, structure, culture), $Z$ is environmental turbulence, and $X_{Z}$ is the optimal value of $X_{1-3}$ as determined by the fit line at point $Z$.

Following Volberda $(1996,1998)$, we use the degree of environmental turbulence to represent the contingency variable. Environmental turbulence is operationalized as the product of the level of dynamism within the market environment and the degree to which changes are unpredictable (see Duncan 1972, Volberda 1998). This definition captures most of the dimensions attributed in definitions of constructs analogous to environmental turbulence, including hypercompetition (e.g., D’Aveni 1994), market dynamism (Davis et al. 2009), and industry clockspeed (Fines 1998, Nadkarni and Narayanan 2007). Technology, structure, and culture represent the response variables. These variables have been used traditionally in contingency research (e.g., Venkatraman and Prescott 1990, Birkenshaw et al. 2002). In line with Volberda (1996, 1998), higher degrees of environmental turbulence would require higher levels of organizational technological, structural, and cultural responsiveness.

When we apply the contingency fit equation to our selection of organizational response variables, deviation 
Volberda et al.: Contingency Fit, Institutional Fit, and Firm Performance

from the optimal fit line will negatively affect firm performance (Donaldson 2001). We thus hypothesize the following.

HyPOTHESIS 1. The contingency fit of the firm's technology, structure, and culture with the level of environmental turbulence of its task environment is positively associated with firm performance.

\section{Institutional Theory, Institutional Fit, and Firm Performance}

Institutional theory examines the influence of the institutional context on organizational behavior (e.g., Scott 2001, Tolbert and Zucker 1996, Wicks 2001) and questions why there is so much homogeneity of organizational forms and practices in an organizational field. DiMaggio and Powell (1983) describe three isomorphic processes-coercive, mimetic, and normative-leading organizations in an organizational field to become increasingly similar. Coercive isomorphism results from political influence and from pressures exerted on organizations by other organizations upon which they depend for resources. Mimetic isomorphism derives from uncertainty and ambiguity about goals. Normative isomorphism derives from professionalization. The three types of isomorphism may reinforce each other, and firms can experience pressures from all three types simultaneously.

Institutional theory suggests that many aspects of organizations are driven by the desire to achieve fit with the institutional environment. Institutional fit has been defined as "the degree of compliance by an organization with the organizational form of structures, routines, and systems prescribed by institutional norms" (Kondra and Hinings 1998, p. 750). The criterion variable that explains performance is legitimacy (of social context), which ensures public support (DiMaggio and Powell 1983, Meyer and Rowan 1977, Zucker 1977). The effects of isomorphic conformity on substantive performance are subject to debate (cf. Heugens and Lander 2009). On the one hand, conformity may conflict with efficiency criteria (e.g., Meyer and Rowan 1977), especially if the required resources for seeking conformity have a higher investment value elsewhere (Barreto and Baden-Fuller 2006), provoke tensions with internal routines, or decrease a firm's potential to differentiate itself from competitors (Heugens and Lander 2009). On the other hand, institutional fit increases organizational legitimacy, which in turn increases performance through different reinforcing mechanisms such as collective learning (Levitt and March 1988) and access to resources (D'Aunno et al. 1991). Collective learning occurs as patterns of cognitive associations and causal beliefs are institutionalized into routines, which are diffused by coercive, mimetic, and normative processes (DiMaggio and Powell 1983, Levitt and March 1988). Adoption of institutionalized routines increases organizational performance by making it more efficient to learn from others than to learn on an individual basis. Insofar as institutional conformity enhances the legitimacy and power of organizations (Meyer and Rowan 1977, Tolbert and Zucker 1983), it can increase their ability to attract resources of higher quality from their environment (e.g., Baum and Oliver 1991, D' Aunno et al. 1991, Deephouse 1999).

From the imperative of institutional fit, organizations tend to follow the behavior of firms that are perceived "more legitimate or successful" (DiMaggio and Powell 1983). We focus on outcome-based imitation, defined as the imitation of organizational design characteristics that produced positive outcomes by other firms in an organizational field (see Haunschild and Miner 1997). Not adopting the organizational design characteristics could signal "illegitimacy" to stakeholders. High performers are assumed to cope effectively with the institutional requirements of the environment. Other firms tend to model themselves on the high performers in their organizational fields, resulting in a high fit with the institutional environment. Despite the potential negative performance effects of institutional conformity, Heugens and Lander (2009) found a positive relationship between conformity, i.e., institutional fit, and substantive (accounting-based) performance when applying a meta-analytical technique. In a study of Japanese enterprise groups, Orru et al. (1991, p. 376) argued, "It is not despite their institutional isomorphism that Japanese enterprise groups are economically fit, but because of the incorporation of institutional elements in their organizations that they are so successful."'

Following the conformity notion of institutional fit, the impact of a firm's organizational design variables on firm performance depends on their similarity to the organizational design variables of high performers in an organizational field, as measured by the following equation:

$$
Y=f\left(\operatorname{abs}\left(X 1^{h}-X 1\right)+\operatorname{abs}\left(X 2^{h}-X 2\right)+\operatorname{abs}\left(X 3^{h}-X 3\right)\right),
$$

where $Y$ is performance, $X 1$ is organizational technology, $X 1^{h}$ is the institutional norm for organization technology in an organizational field, $X 2$ is organizational structure, $X 2^{h}$ is the institutional norm for organization structure in an organizational field, $X 3$ is organizational culture, and $X 3^{h}$ is the institutional norm for organization culture in an organizational field.

Assessing institutional fit requires the determination of the organizational design profile of high-performing firms (in terms of technology, structure, and culture) because those firms are assumed to have reached fit with the institutional context (Kondra and Hinings 1998). Institutional misfit, determined as the sum of the absolute deviations of these variables from the values as evident for high-performing firms, will have negative effects on firm performance. 
HYPOTHESIS 2. The institutional fit of the firm's technology, structure, and culture with those of highperforming firms in its organizational field is positively associated with firm performance.

\section{Complementary Linkages Between Contingency Fit and Institutional Fit}

Although contingency theory and institutional theory use different conceptualizations of fit, both perspectives are open systems theories (Ashby 1956, Scott 2003, Von Bertalanffy 1951). In open systems theory, the basic principle that explains performance is synergy derived from the sum of interconnected elements (Siggelkow 2001). Synergy in contingency theory refers to the interconnection of the organization with specific environmental demands, whereas synergy in institutional fit refers to the interconnection of the organization with the uniform institutional demands of the industry environment. Contingency and institutional fit approaches are both coalignment approaches that focus on different types of synergy between the organization and its environment. Therefore, a combination of these approaches might better explain firm performance than either approach in isolation.

There have been several discussions in the literature of the complementarities of contingency and institutional theory. Gupta et al. (1994), drawing on both contingency and institutional theory, demonstrated that the two perspectives can be combined to study the effect of institutional forces on work unit performance. From a sociological view, Carroll (1993) used the adaptationselection perspective to explain firms' successes and suggested complementarities between contingency and institutional theories for the understanding of the homogeneity or heterogeneity of firms in different industries. Other studies have combined both theories to explain the organizational change and performance in transition economies, considering the institutional constraints from the firms' former political systems. Child et al. (2003) analyzed a large sample of firms in Hong Kong who were managing operations in China. They used alternative perspectives (e.g., natural selection, strategic adaptation, and contingency) to explain business performance and reported empirical evidence that each of the following factors significantly influence firm performance: business and institutional environment, strategic managerial action, and the fit between firm organization and environmental contingencies. They also discussed the complementarities of the perspectives: "Although the business and institutional environments do have a significant influence on the performance of the crossborder affiliates in a transition economy, performance can be improved through strategic managerial action" (Child et al. 2003, p. 253). Finally, Clark and Soulsby (1995) argued that contingency and institutional theories complement each other to improve understanding of organizational change among former enterprises in the Czech Republic. They argued that new managerial conduct coexists with the inertia of old practices that limit organizational change.

These contributions support the notion that both fit approaches are complementary. Therefore, we posit that taking into account both the synergies of the organization with specific task environmental demands and its synergies with uniform institutional demands of the organizational field should better explain firm performance than taking either approach in isolation. This gives rise to our third hypothesis.

HyPOTHESIS 3. The simultaneous coalignment of the firm's technology, structure, and culture with its specific task environment and uniform institutional demands of its organizational field is positively associated with firm performance.

\section{Interdependence Between Contingency Fit and Institutional Fit}

Contingency and institutional approaches refer to different types of synergy of the organization with the environment. From an institutional perspective, isomorphic processes at industry level lead to the adoption of a "conformance-enhancing template" (Heugens and Lander 2009, p. 64). The theory treats organizations as sets of interdependent members with common patterns of cognition and beliefs (Argyris and Schon 1978, DiMaggio 1991, Weick 1979). Contingency theory, however, refers to the specific task environment and treats organizations as goal-oriented activity systems that learn to coalign with the demands of a specific environment by repeating successful behaviors and discarding unsuccessful ones (Cyert and March 1963, Levinthal 1991, March 1981). The two approaches assume different requirements for fit that are complementary to some extent but also may place paradoxical demands on the organization (Donaldson 2008b). Indications of a potential trade-off between contingency and institutional fit are reported by Lee and Miller (1996), who found that both contingency prescriptions and conformity to institutional pressures could explain high firm performance in the same industry. Firms using traditional technologies could benefit from government interventions, and those firms that employ emergent technologies could benefit from heeding contingency prescriptions. The conclusions suggest that firms can substitute or trade-off different strategies (internal organizational effectiveness versus external legitimacy and support) to achieve success. However, this does not imply that the impact of these strategies is fully independent.

In a review of the literature, we find some evidence to suggest that contingency fit and institutional fit are interdependent. Greening and Gray (1994) analyzed the variability of organizational structures in responding to 
the environment by comparing institutional theory and resource dependence theory. The authors proposed a contingency model that integrates the institutional pressures on firm structures with the managerial discretion within the constraints of other organizations that control critical resources for them. Other studies advocate some contingency properties in institutional theory. Boiral (2003), analyzing the ISO 9000 standard implementation, discovered that institutional pressures that cause organizations to become isomorphic as they adopt identical models are reinterpreted and modified within organizations, based on managers' personal opinions and attitudes. Washington and Ventresca (2004) found that the institutional environment can actually support changes in organizational strategy and does not merely constrain or pressurize organizations to conform as understood inside the "iron cage" (DiMaggio and Powell 1983). The authors present an alternative view of institutional isomorphism in which institutional process mechanisms can facilitate organizational change. These contributions, which demonstrate the interrelationship between contingency fit and institutional fit, support the notion that it is beneficial to study interdependencies between both fit approaches in order to explain firm performance.

Deviation from a socially accepted common set of evaluation routines may be accepted if organizational practices produce positive outcomes (Haunschild and Miner 1997). Practices or organizational structures that deviate from institutional norms but produce positive organizational outcomes are more likely to be accepted and receive external support (Griliches 1957). Under uncertain conditions, institutional norms may be used partly as a substitute for information or for the capability to recognize effective organizational practices. For external parties, institutional norms such as ISO norms are the "second-best" indicators of organizational effectiveness. However, their value may be considerably less when other evidence of organizational effectiveness is available. For example, a bank or shareholders may be inclined to provide capital to a company that conforms to industry norms and routines. Given the imperfections of capital markets, this is an important source of information on the reliability and professionalism of organizational practices. However, a company that has demonstrated high organizational effectiveness may also be recognized as acceptable and receive external support from shareholders and banks, even if the company deviates substantially from industry norms and practices. The value of the second-best information provided by institutional conformism is reduced when the firm has proven its effectiveness through high performance. Thus, the relevance of the impact of institutional requirements on firm performance may be reduced substantially under high levels of contingency fit.

HyPOTHESIS 4. Contingency fit moderates the relation between institutional fit and firm performance such that there will be a weaker, negative relationship between institutional misfit and firm performance when contingency fit is high.

\section{Data and Method}

\section{Sample}

Fit research encompasses both the relationship between fit and performance and the adaptation process toward organizational fit. In our research, we focus on the performance implications of fit. Therefore, we need a large cross-sectional sample with substantial variation in organizational and environmental variables. We use a unique large-scale cross-sectional sample of firms across a wide range of industries and firm size classes to test our hypotheses. The sample contains survey and archival data on 3,259 responses from a panel of 1,904 organizations across 13 different industries. The distribution of firms across industries and firm size classes is presented in Table 1. All firms are active in the Netherlands and have at least 10 employees. Survey data for the database were collected mainly around the year 2002 using a structured questionnaire. All respondents held management positions in these firms. For 149 organizations, we have multi-informant data (ranging from 2 to 95 respondents per firm), which allowed us to examine interrater reliability and interrater agreement. Using this subset, we calculated an interrater agreement score, $r_{w g}$, for each study variable (James et al. 1993). The median interrater agreement ranged from 0.68 to 0.80 , which exceeds the level of 0.60 required to justify the use of an aggregated perceptual measure (Glick 1985). In addition, examination of within-group reliability coefficients revealed a strong level of interrater reliability (Jones et al. 1983), with $\alpha$ values ranging from 0.75 to 0.93 .

Survey measures are more appropriate for explaining managerial behavior than archival measures (Bourgeois 1980). However, a disadvantage of survey information is that the source (the respondent) explains variance between variables, which may partly explain the study's results. To examine whether such common method bias may augment relationships, we first performed Harman's one-factor test on the self-reported items of the latent constructs included in our study. The hypothesis of one general factor underlying the relationships was rejected $(p<0.01)$. In addition, we found multiple factors, and the first factor did not account for the majority of the variance. However, this test has several limitations (Podsakoff et al. 2003), so we conducted three additional tests. First, we found a model fit of the measurement model greater than 0.90 , which suggests no problems with common method bias (Bagozzi et al. 1991). Second, the smallest observed correlation among the model variables can function as a proxy for common method bias (Lindell and Brandt 2000). The smallest correlation between the model variables is 0.06 , which does 
Table 1 Industry and Firm Size Distribution of Sample

\begin{tabular}{lc} 
Industry & Percentage \\
\hline Agriculture, forestry, fishing, & 3 \\
$\quad$ and hunting & 5 \\
Mining & 17 \\
Manufacturing & 3 \\
Utilities & 6 \\
Construction & 1 \\
Accommodation and food services & 11 \\
Transportation, retail, and & \\
$\quad$ warehousing & 10 \\
Financial services & 28 \\
Professional services and leasing & 6 \\
Government and social security & 3 \\
Education & 5 \\
Health care and social assistance & 2 \\
Arts, entertainment, recreation, & \\
$\quad$ and other services & \\
\hline Number of employees & 7 \\
\hline 10-20 & 13 \\
$21-50$ & 34 \\
$51-250$ & 18 \\
$251-1,000$ & 28 \\
>1,000 & $n=3,259$ \\
Total &
\end{tabular}

not suggest the presence of common method bias. Third, we performed a partial correlation method (Podsakoff and Organ 1986), adding the highest factor between an unrelated set of items and each predictor variable to the model. These factors did not produce a significant change in variance explained, again suggesting no substantial common method bias. In sum, we conclude that the evidence from a variety of methods supports the assumption that common method bias does not account for the study's results.

\section{Construct Measurement}

We generated an initial list of Likert-type items based on the definitions of the constructs and on our review of the literature relating to these dimensions. Exploratory interviews with management consultants and audits within various firms then served as a basis for item generation and content validity assessment. For technology of the firm, i.e., the hardware (such as machines and equipment) and software (knowledge) used in transforming inputs into outputs (Volberda 1996), we used items adapted from the work of Hill (1983), Perrow (1967), and Hickson et al. (1969). For organizational structure, comprising the actual distribution of responsibilities and authority among the organization's personnel and the process regulations of decision making, coordination, and execution, indicators were adapted from Burns and Stalker (1961), Pugh et al. (1963), Lawrence and Lorsch (1967), Mintzberg (1979), and Hrebiniak and Joyce (1985). Items related to organizational culture, defined as the set of beliefs and assumptions held relatively commonly throughout the organization and taken for granted by its members (Bate 1984), were based on the work of Ouchi (1979), Camerer and Vepsalainen (1988), and Hofstede et al. (1990). Items reflecting the construct of environmental turbulence, i.e., the product of unpredictability and dynamism in the environment, were adapted from Dill (1958), Duncan (1972), Lawrence and Lorsch (1967), and Thompson (1967).

Archival data on firm performance were available for a number of firms. Because survey measures of performance correlate quite highly with archival measures in organizations (Dess and Robinson 1984), we measured firm performance using a scale with three survey items adopted from Jaworski and Kohli (1993). We compared the survey data of our performance scale with the available accounting performance data and calculated intercoder agreement and intercoder reliability scores. The survey measure appears to correlate highly with return on assets (Pearson correlation of $0.69 ; p<0.01$ ). Both the interrater agreement score (James et al. 1993) and the interrater reliability score (Jones et al. 1983) for this scale are adequate, with a median $r_{w g}=0.76$ and an average within-group $\alpha$ coefficient of 0.95 .

\section{Control Variables}

In our model, we include control variables for firm size and industry effects. Researchers have identified organizational size as a critical variable moderating the relationship between strategy and performance (Dobrev and Carroll 2003, Hofer 1975, Smith et al. 1989). Firm size is measured by the number of organizational members to be organized (Blau 1970) as reported in the firm's financial reports. Furthermore, because the impact of particular production technologies may vary substantially between types of industries, we control for industry effects by including dummy variables for industrial firms, trade firms, service firms, nonprofit organizations, and a miscellaneous category.

\section{Item Selection}

We first investigated the psychometric properties of the scales using exploratory factor analysis on a subset of firms. We analyzed each dimension of the scales using principal component procedures and varimax rotation to assess their unidimensionality and factor structure. Only items that satisfied the following criteria were included: (1) items should have communality higher than 0.3 , (2) dominant loadings should be greater than 0.5 , (3) cross-loadings should be lower than 0.3 , and (4) the scree plot criterion should be satisfied (Briggs and Cheek 1988).

We assessed the reliabilities of the scales by means of the Cronbach $\alpha$ coefficient and the construct reliability. Reliability scores vary between 0.67 and 0.84 (see Table 2), which exceeds the commonly used threshold 
Table 2 Items and Constructs

\begin{tabular}{|c|c|c|}
\hline Constructs & $\begin{array}{l}\text { Factor } \\
\text { loadings }\end{array}$ & $\begin{array}{l}\text { Item correlation } \\
\text { with total score }\end{array}$ \\
\hline \multicolumn{3}{|l|}{ Nonroutine technology $(\alpha=0.67$, composite reliability $=0.80, \mathrm{AVE}=0.50)$} \\
\hline The layout and setup of our primary process can be changed easily. & 0.63 & 0.67 \\
\hline Our equipment and information systems can be used for multiple purposes. & 0.77 & 0.76 \\
\hline Our employees master several methods of production and operations. & 0.81 & 0.78 \\
\hline Our organization is up to date regarding "know-how." & 0.61 & 0.61 \\
\hline \multicolumn{3}{|l|}{ Organic structure $(\alpha=0.75$, composite reliability $=0.84, \mathrm{AVE}=0.58)$} \\
\hline $\mathrm{R}$ Our organization uses extensive and structured systems for planning and control. & 0.72 & 0.72 \\
\hline $\mathrm{R}$ In our organization, the division of work is defined in detailed descriptions of jobs and tasks. & 0.83 & 0.81 \\
\hline $\mathrm{R}$ In our organization, everything has been laid down in rules. & 0.85 & 0.83 \\
\hline $\mathrm{R}$ In our organization, there are a lot of consultation bodies. & 0.63 & 0.67 \\
\hline \multicolumn{3}{|l|}{ Innovative culture $(\alpha=0.70$, composite reliability $=0.82, \mathrm{AVE}=0.54)$} \\
\hline $\begin{array}{l}\text { R For our organization, the following applies: "The rules of our organization can't be broken, } \\
\text { even if someone believes that it is in the company's best interest." }\end{array}$ & 0.68 & 0.72 \\
\hline \multirow{2}{*}{$\mathrm{R}$ Deviating opinions are not tolerated in our organization. } & 0.84 & 0.81 \\
\hline & 0.65 & 0.68 \\
\hline $\begin{array}{l}\mathrm{R} \text { The person that introduces a less successful idea in our company can forget about his or her } \\
\text { career. }\end{array}$ & 0.76 & 0.72 \\
\hline \multicolumn{3}{|l|}{ Market dynamism $(\alpha=0.84$, composite reliability $=0.88, \mathrm{AVE}=0.56)$} \\
\hline Changes in our market are very intense. & 0.73 & 0.72 \\
\hline In our market, customers frequently demand completely new products and/or services. & 0.74 & 0.73 \\
\hline In the market we operate in, changes happen continuously. & 0.81 & 0.80 \\
\hline Our offering of products/services to our customers changes constantly. & 0.75 & 0.74 \\
\hline In our market, the amount of products and/or services to be supplied changes often and quickly. & 0.73 & 0.74 \\
\hline In the market we operate in, each day something changes. & 0.71 & 0.73 \\
\hline \multicolumn{3}{|l|}{ Unpredictability of changes $(\alpha=0.75$, composite reliability $=0.81, \mathrm{AVE}=0.47$ ) } \\
\hline $\mathrm{R}$ Of what happens in our market, nothing remains unknown to us. & 0.73 & 0.71 \\
\hline $\mathrm{R}$ Information that we need concerning our market, we are bound to get. & 0.81 & 0.79 \\
\hline In our market, it is hard to make decisions based on reliable information. & 0.51 & 0.58 \\
\hline $\mathrm{R}$ We have sufficient information about our competitors. & 0.68 & 0.69 \\
\hline $\mathrm{R}$ We have sufficient insight and information about our customers. & 0.67 & 0.66 \\
\hline \multicolumn{3}{|l|}{ Firm performance $(\alpha=0.83$, composite reliability $=0.89, \mathrm{AVE}=0.74)$} \\
\hline Our organization is very profitable. & 0.77 & 0.82 \\
\hline In comparison with similar organizations, we are doing very well. & 0.91 & 0.88 \\
\hline Our competitors can be jealous of our performance. & 0.89 & 0.87 \\
\hline
\end{tabular}

Note. $\mathrm{R}$, reversed item.

value of 0.60 for exploratory research (Nunnally 1967). Variables with relatively low reliability are technology $(\alpha=0.67)$ and culture $(\alpha=0.70)$. These variables are relatively broad in conceptual scope (i.e., constructs defined by two or more distinct elements or underlying dimensions). However, their reliability sufficiently exceeds the threshold level of 0.55 recommended for such constructs by Van de Ven and Ferry (1980). In addition, composite reliabilities range between 0.80 and 0.85 , which is above the 0.70 commonly used threshold value, and average variance extracted (AVE) measures exceed the 0.50 value (Hair et al. 1998).

Each construct contains three to six items and was measured on a seven-point Likert scale. We used confirmatory factor analysis with EQS version 6.1 to validate the scales resulting from the exploratory factor analysis. A satisfactory fit was achieved with a root-mean-square estimated residual (RMSEA) of 0.05 and confirmatory factor index (CFI) of 0.94. The CFI of 0.94 is considered an indication of good fit, and the RMSEA of 0.05 indicates good model fit as it does not exceed the critical value of 0.08 (Bentler and Bonett 1980). We verified the discriminant validity of the scales by comparing the highest shared variance between any of the two constructs and the variance extracted from each of the constructs (Hair et al. 1998). In all cases, each construct's AVE is larger than its correlations with other constructs, supporting the discriminant validity of the measurement model (Fornell and Larcker 1981). In addition, none of the confidence intervals of the correlation coefficients between any of the constructs included 1.0 (Anderson and Gerbing 1988). Given this collection of supporting indices, we conclude that the measurement model is acceptable.

\section{Results}

This section presents the findings of our tests concerning Hypotheses 1-4. First, Table 3 presents descriptive statistics and correlations of our variable set. 


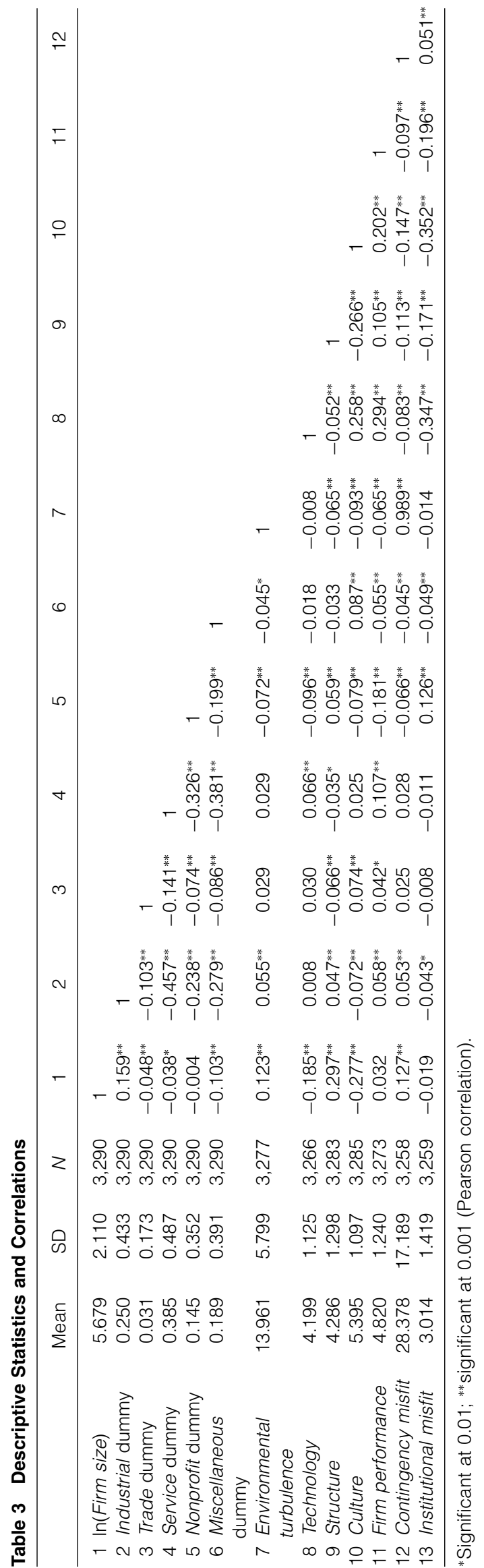

To test Hypothesis 1, which deals with the performance effects of contingency misfit, we followed the two-step procedure described previously. First, the approximate fit line is established as a line in which the level of the organization design variable equals that of the contingency variable (environmental turbulence). Misfit is then calculated as the deviation of a response variable from this particular fit line. Contingency misfit is the sum of the deviations of the response variables technology, structure, and culture. Subsequently, we regressed the summated misfit on organizational performance. Model 2 in Table 4 presents the regression results of contingency misfit on firm performance. Controlling for firm size and a set of industry characteristics, we found significant negative performance effects of contingency misfit $(\beta=-0.120, p<0.001)$. In addition, contingency misfit of the three design variables in our study explains a substantial (1.4\%) and significant additional variance of organizational performance. Finally, contingency misfit remains stable in the models where we add institutional misfit (Models 4 and 5). Overall, the results strongly support Hypothesis 1, even when we take institutional factors regarding the design variables of our study into account.

To test our second hypothesis on the performance consequences of institutional misfit, the average values of the organizational design variables (technology, structure, and culture) were calculated for a subsample of high-performing firms ( $Z$-score for firm performance, $\geq 1.5$ ) for each industry category in our sample. More specifically, for each firm we analyzed whether it is an industrial firm, trade firm, service firm, or a nonprofit firm. Accordingly, we created four subsamples of highperforming firms in each of the four industry categories. For the remaining sample of firms $(Z$-score for firm performance, $<1.5$ ), the sum of the absolute deviations from the three organization design variables (technology, structure, and culture) of the high performers in each industry category represents institutional misfit. Model 3 in Table 4 presents the results of the regression analysis of institutional misfit on firm performance. The coefficient of institutional misfit is significant and negative $(\beta=-0.190, p<0.001)$. The additional variance explained by institutional misfit is substantial (3.3\%) and highly significant. Also, when we take the contingency misfit into account in Models 4 and 5, the impact of institutional misfit remains robust. We also tested the robustness of our model using a larger subset of highperforming firms ( $Z$-score for firm performance, $\geq 1.0$ ). This model with a broader set of high performers as the norm shows similar results $(\beta=-0.19, p<0.001)$. Overall, these results strongly support Hypothesis 2 of our theoretical framework.

Having found that contingency misfit and institutional misfit separately affect firm performance, we next examined the simultaneous impact of these fit approaches 
Volberda et al.: Contingency Fit, Institutional Fit, and Firm Performance

Organization Science 23(4), pp. 1040-1054, (C) 2012 INFORMS

Table 4 Hierarchical Regression of Controls and Theory Variables on Firm Performance

\begin{tabular}{|c|c|c|c|c|c|c|}
\hline \multirow{3}{*}{ Constant } & \multirow{3}{*}{$\begin{array}{c}\text { Model 1 } \\
\text { (Controls) } \\
\beta(\mathrm{SE}) \\
4.599(0.073)^{* * *}\end{array}$} & \multirow{3}{*}{$\begin{array}{c}\text { Model } 2 \\
\frac{(\text { Fit line deviation) }}{\beta(\mathrm{SE})} \\
4.785(0.077)^{* * *}\end{array}$} & \multirow{3}{*}{$\begin{array}{c}\text { Model } 3 \\
\frac{(\text { Profile deviation) }}{\beta(\mathrm{SE})} \\
4.999(0.081)^{* * *}\end{array}$} & \multirow{2}{*}{$\begin{array}{c}\text { Model } 4 \\
\frac{(\text { Complementary model) }}{\beta(\mathrm{SE})}\end{array}$} & \multirow{2}{*}{\multicolumn{2}{|c|}{$\begin{array}{c}\text { Model } 5 \\
\frac{(\text { Interaction model) }}{\beta(\mathrm{SE})}\end{array}$}} \\
\hline & & & & & & \\
\hline & & & & $5.211(0.087)^{* * *}$ & 5.193 & $(0.087)^{* * *}$ \\
\hline In(Firm size $)$ & $0.025(0.010)$ & $0.040 \quad(0.010)^{* *}$ & 0.025 (0.010) & $0.035(0.010)^{* *}$ & 0.034 & $(0.010)^{* *}$ \\
\hline Industrial firms & $0.090(0.066)^{* * *}$ & $0.096(0.065)^{* * *}$ & $0.081(0.062)^{* * *}$ & $0.098(0.064)^{* * *}$ & 0.097 & $(0.064)^{* * *}$ \\
\hline Trade firms & $0.062(0.130)^{* * *}$ & $0.067 \quad(0.130)^{* * *}$ & $0.047(0.127)^{* *}$ & $0.068 \quad(0.128)^{* * *}$ & 0.067 & $(0.127)^{* * *}$ \\
\hline Service firms & $0.120(0.060)^{* * *}$ & $0.126(0.060)^{* * *}$ & $0.106(0.057)^{* * *}$ & $0.133(0.059)^{* * *}$ & 0.132 & $(0.059)^{* * *}$ \\
\hline Nonprofit firms & $-0.118(0.075)^{* * *}$ & $-0.121(0.074)^{* * *}$ & $-0.102(0.071)^{* * *}$ & $-0.097(0.074)^{* * *}$ & -0.097 & $(0.074)^{* * *}$ \\
\hline Contingency misfit & & $-0.120(0.001)^{* * *}$ & & $-0.109(0.001)^{* * *}$ & -0.102 & $(0.001)^{* * *}$ \\
\hline Institutional misfit & & & $-0.190(0.014)^{* * *}$ & $-0.151 \quad(0.015)^{* * *}$ & -0.167 & $(0.015)^{* * *}$ \\
\hline Interaction term & & & & & -0.062 & $(0.020)^{* * *}$ \\
\hline$R^{2}$ & $0.043^{* * *}$ & $0.057^{* * *}$ & $0.076^{* * *}$ & $0.086^{* * *}$ & & $90^{* * * *}$ \\
\hline$\Delta R^{2}($ Model 1) & & $0.014^{*}$ & $0.033^{* * *}$ & $0.043^{* * *}$ & & $47^{* * *}$ \\
\hline$\Delta R^{2}$ (Model 2) & & & $0.019 * *$ & $0.029^{* *}$ & & $33^{* * *}$ \\
\hline$\Delta R^{2}$ (Model 3) & & & & $0.010^{*}$ & & $014^{* *}$ \\
\hline$\Delta R^{2}$ (Model 4) & & & & & & $004^{*}$ \\
\hline$F$ & 29.180 & 32.698 & 42.187 & 43.547 & & 9.950 \\
\hline$N$ & 3,243 & 3,243 & 3,099 & 3,243 & & 243 \\
\hline
\end{tabular}

${ }^{*} p<0.05 ;{ }^{* *} p<0.01 ;{ }^{* * *} p<0.001$

on firm performance. Model 4 in Table 4 shows the simultaneous impact of contingency misfit and institutional misfit. In support of Hypothesis 3, the results show that both fit approaches simultaneously affect firm performance. Interestingly, contingency misfit $(\beta=$ $-0.109, p<0.001)$ and institutional misfit $(\beta=-0.151$, $p<0.001)$ both have a significant impact on firm performance; however, the size of the coefficient of institutional misfit is higher. Because the correlation between the two fits is very low (0.051) and Variance Inflation Factor scores are below 2, the results are not influenced by multicollinearity. If we estimate the difference between the coefficients of the misfit, then the difference is statistically significant at the 5\% level, suggesting that for our three organizational design variables, institutional misfit has a larger impact on firm performance than contingency misfit.

Finally, we examined the hypothesized negative moderating effect of contingency fit on the relationship between institutional fit and performance (Hypothesis 4). From Model 5 in Table 4, it appears that the interaction term is indeed significant and negatively related to performance $(\beta=-0.062, p<0.01)$, and the individual misfit measures remain significant. When comparing Model 5 with Models 1-4, the model is superior in explanatory power. These results support Hypothesis 4 of our theoretical framework.

To illustrate the impact of our findings, the interactions between these two types of misfit have been plotted in Figure 1. Figure 1 shows the performance effects of changes in institutional misfit both for firms with low contingency misfit (good fit) and high contingency misfit (bad fit). Both slopes are negative, which implies that deviating from the organizational design of high performers reduces firm performance. However, the slope is clearly less steep for firms aligned to their task environment, i.e., firms with low contingency misfit. This result suggests that when firms enjoy good contingency fit, the effects of institutional misfit weaken compared to when firms suffer from high contingency misfit.

To gain further insights into the interaction effect between institutional fit, contingency fit, and performance, we plotted the significant results obtained from Model 5 of Table 4 in a three-dimensional (3D) graph (see Figure 2). The 3D graph perfectly illustrates that firms with high institutional and contingency misfit (the blue and green areas) will have low performance and can substantially raise their performance by improving institutional and/or contingency fit. Firms with high institutional and contingency fit are on a performance

Figure 1 Performance Effects of Institutional Fit

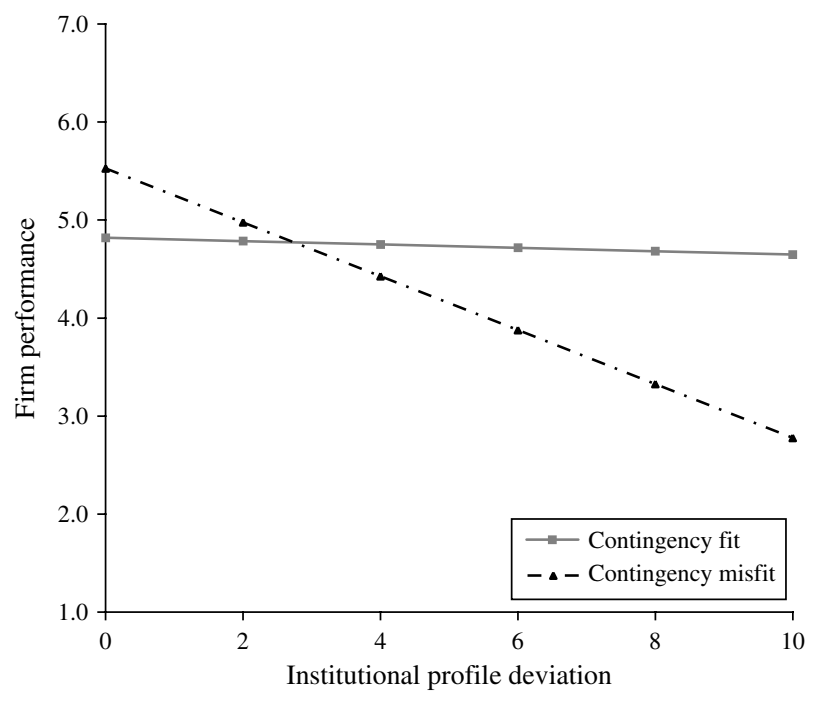


Figure 2 Landscape of the Effects of Interaction of Institutional Misfit and Contingency Misfit on Firm Performance

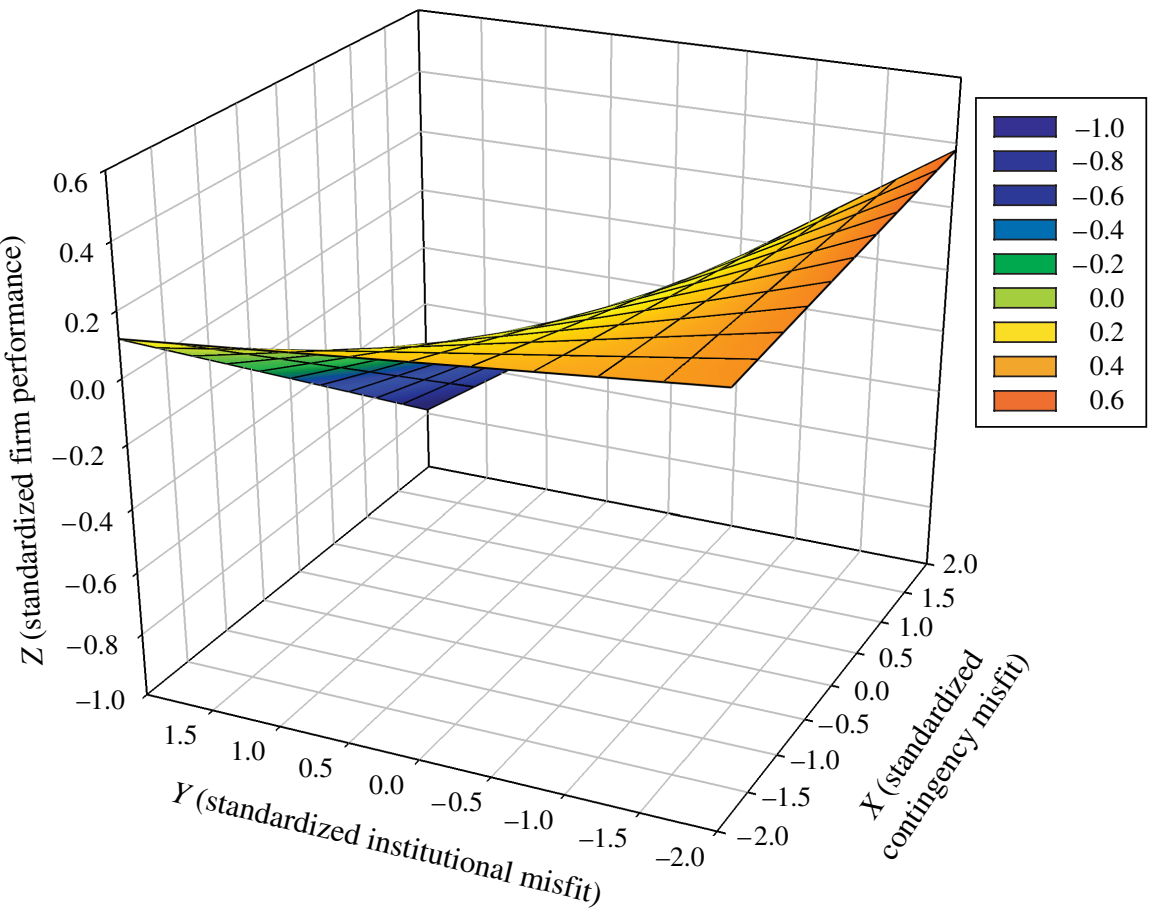

3D landscape of (standardized) misfit interactions

peak (the orange area). However, those firms with perfect contingency fit and large institutional misfit (coordinates $(-2,0 ; 2,0)$, or the left peak in the graph) can only marginally improve their performance when they increase their institutional fit (movement from $(-2,0 ; 2,0)$ to $(-2,0 ;-2,0)$ along the $Y$ axis). Quite counterintuitively, those firms with an extreme institutional fit and low contingency fit (coordinates $(2,0 ;-2,0)$, or the right peak in the graph) will lower their extreme high performance when they increase their contingency fit (movement from $(2,0 ;-2,0)$ to $(-2,0 ;-2,0)$ along the $X$ axis).

\section{Discussion}

In this paper, we set out to address a fundamental debate in the strategic management literature on the relationship of the organization to its business environment, with the goal of contributing to the development of a unifying theory on the relationship between organizational fit and performance. Scholars from different schools of thought have used the concept of fit to indicate sources of synergy between the organization and its business environment, a concept that originates from open systems theory. Fit has been adopted as a key element explaining organizational performance within both contingency and institutional theories. Within a large sample of 3,259 respondents from 1,904 firms operating in 13 different industries, we found strong support for the notion that the combined insights of both theories produce a superior explanation of firm performance than each theory in isolation. The results of this study imply that each of these perspectives provides a partial explanation of the synergetic effects between organizational and environmental elements, and that contingency and institutional fit interact in the formation of firm performance. This supports the notion of metafit proposed by Donaldson (2008a), which suggests that a sound and fully comprehensive organizational design analysis should supplement contingency analysis with institutional analysis. Managers may benefit from considering elements of both perspectives simultaneously to chart a course of action toward improved organizational performance. At the same time, managers must resolve inconsistencies between these perspectives by carefully considering the context of their specific firms. When redesigning internal organization elements to optimize synergy, they need to scan and interpret both the contingencies of their specific business environment and the institutional requirements of their industry.

By pursuing institutional fit, managers can help the firm gain legitimacy through isomorphic processes. In this way, managers create synergy between the firm and the institutional environment. Moreover, regardless of the pressures from the institutional environment, managers can also achieve high performance by searching for contingency fit. If contingency fit is not in line with institutional requirements, however, firms may need to balance internal organizational effectiveness with the need for external legitimacy and support. Institutional processes partly substitute for a lack of capabilities and 
information on organizational effectiveness (Volberda et al. 2010). However, by developing high levels of contingency fit, managers also develop a basis for external legitimacy and support. Therefore, under high contingency fit when organizational effectiveness is high and observable by external parties, the impact of institutional misfit on performance is reduced. The relevance of institutional pressures therefore particularly applies to organizations that have yet to demonstrate their effectiveness.

The relevance of our metafit approach particularly applies under conditions of persistent "quasi fit" (Donaldson 2001), rather than where there is perfect contingency fit or optimal institutional fit. If we accept the assumption of quasi fit, the strategic discretion of most firms is limited to the right side of Figure 1, where the moderating impact of contingency fit is largest. Here, organizations face trade-offs between internal organizational effectiveness and external legitimacy and support in their organizational design. Similar conditions are also likely to apply where firms face suddenly unfamiliar task and institutional environments, such as in cases of radical innovation, internationalization, unrelated diversification, and radical regulatory reform. Although firms may be tempted first to increase fit with their specific task environment, they may be better off first decreasing institutional misfit, which substantially reduces the negative impact of contingency misfit on firm performance (see Figure 1). Addressing this sequencing question of choosing whether to improve contingency fit by adaptation to the specific task environment, to invest in an improved institutional fit by copying organizational designs of high-performing firms, or to improve both simultaneously is a fundamental strategic organizational design issue. Our findings show that for all these firms under quasi fit (firms in the blue and green areas in Figure 2), improvements in either fit or the joint optimization of these fits will result in increased performance.

Nonetheless, our results also show that for firms with a perfect contingency fit or an optimal institutional fit, our metafit approach is more of a conflicting mode than a complementary mode; that is, in situations of high contingency fit where the firm specializes in one fit by completely adapting to its specific task environment to improve internal organizational effectiveness, investments in simultaneously improving institutional fit to increase external legitimacy and support will only result in marginal improvements of performance (see the continuous line in Figure 1 with low contingency misfit and the left peak with coordinates $(-2,0 ; 2,0)$ in Figure 2). What emerges even more clearly is that firms that are able to realize an extreme institutional fit by copying the organizational designs of high performers in their particular industry to gain legitimacy and support should not simultaneously invest in improving their contingency fit (the right peak with coordinates $(2,0 ;-2,0)$ in Figure 2). Such specific adaptations to their task environment will even lower their performance (see the left side of Figure 1, in which firms with low institutional misfit that decrease their contingency misfit move from the dashed line to the continuous line with lower performance). It should be noted that the number of firms with high institutional fit is very limited in our sample and is thus an exceptional case. Nonetheless, if these highly institutionalized firms want to flourish, they should probably just focus on following best practices on organization design in their industry and not distract themselves by trying to adapt to every little whim of the market. All in all, firms under quasi fit instead of perfect fit may improve their performance by investing in increased contingency fit, increased institutional fit, or both. However, firms with perfect contingency or perfect institutional fit should go for a specialization strategy. Figure 2 shows that a high performance peak can be achieved by a single high contingency fit, a single high institutional fit, or acceptable levels of both fits.

Of course, the results of our study are subject to several limitations that need to be taken into account when interpreting the results. First, our sample is large but only contains firms that are active in the Netherlands, which could represent a potential source of bias in our results and therefore needs validation in other contexts. Second, respondents have not been invited to fill out the survey in subsequent years. Such an analysis might shed more light on time effects in fit-performance relationships. Finally, although our study has shown that contingency and institutional fit are interdependent, the development process toward metafit remains largely unexplored. The next step would be to explore the implications for dynamic institutional isomorphic or firm adaptation processes (e.g., Williams 2008, Volberda and Lewin 2003) toward metafit. Understanding the dynamics of firm adaptation and institutional forces toward metafit could further advance our understanding of how different coevolutionary development paths influence the relationship between institutional mechanisms, contingency fit, and firm performance (Lewin and Volberda 1999, Volberda and Lewin 2003).

In sum, drawing on contingency and institutional theory, this study demonstrated that most firms under quasi fit in search of high performance need to adapt to the task environment while simultaneously taking into account institutional constraints (isomorphism). These perspectives are complementary and interact in what might be called metafit (Donaldson 2008a). However, firms with a high contingency fit should pay less attention to institutional constraints because achieving an institutional fit at the same time will only slightly increase their performance. For firms that have achieved a perfect institutional fit, adapting to the specifics of their task environment might even decrease their performance. Exploring these dynamic coevolutionary processes of specific firm adaptations and more generic institutional forces at industry level will be a fruitful subject for future research. 


\section{Acknowledgments}

The authors are grateful to the senior editor, Rich Burton, for his valuable feedback and guidance and to the three anonymous reviewers. They also thank Ed Zajac for his helpful comments on an earlier version of this paper.

\section{References}

Anderson, J. C., D. W. Gerbing. 1988. Structural equation modelling in practice: A review and recommended two step approach. Psych. Bull. 103(3) 411-423.

Argyris, C., D. A. Schon. 1978. Organizational Learning: A Theory in Action Perspective. Addison-Wesley, Reading, MA.

Ashby, W. R. 1956. An Introduction to Cybernetics. Chapman \& Hall, London.

Bagozzi, R. P., Y. Yi, L. W. Phillips. 1991. Assessing construct validity in organizational research. Admin. Sci. Quart. 36(3) 421-458.

Barreto, I., C. W. F. Baden-Fuller. 2006. To conform or to perform? Mimetic behaviour, legitimacy-based groups and performance consequences. J. Management Stud. 43(7) 1559-1581.

Bate, P. 1984. The impact of organizational culture on approaches to organizational problem-solving. Organ. Stud. 5(1) 43-66.

Baum, J. A. C., C. Oliver. 1991. Institutional linkages and organizational mortality. Admin. Sci. Quart. 36(2) 187-218.

Bentler, P. M., D. G. Bonett. 1980. Significance tests and goodness of fit in the analysis of covariance structures. Psych. Bull. 88(3) 588-606.

Birkinshaw, J., R. Nobel, J. Ridderstråle. 2002. Knowledge as a contingency variable: Do the characteristics of knowledge predict organization structure? Organ. Sci. 13(3) 274-289.

Blau, P. M. 1970. A formal theory of differentiation in organizations. Amer. Sociol. Rev. 35(2) 201-218.

Boiral, O. 2003. ISO 9000: Outside the iron cage. Organ. Sci. 14(6) $720-737$.

Bourgeois, L. J., III. 1980. Performance and consensus. Strategic Management J. 1(3) 227-248.

Briggs, S. R., J. M. Cheek. 1988. On the nature of self-monitoring: Problems with assessment, problems with validity. J. Personality Soc. Psych. 54(4) 663-678.

Burns, T., G. M. Stalker. 1961. The Management of Innovation. Tavistock, London.

Burton, R. M., B. Obel. 2004. Strategic Organizational Diagnosis and Design: The Dynamics of Fit. Kluwer Academic Publishers, Dordrecht, The Netherlands.

Burton, R. M., J. Lauridsen, B. Obel. 2002. Return on assets loss from situational and contingency misfits. Management Sci. 48(11) 1461-1485.

Burton, R. M., J. Lauridsen, B. Obel. 2003. Erratum: Return on assets loss from situational and contingency misfits. Management Sci. 49(8) 1119.

Burton, R. M., B. H. Erikson, D. D. Håkonsson, T. Knudsen, C. C. Snow, eds. 2008. Designing Organizations: 21st Century Approaches. Springer, New York.

Camerer, C., A. Vepsalainen. 1988. The economic efficiency of corporate culture. Strategic Management J. 9(S1) 115-126.

Carroll, G. R. 1993. A sociological view on why firms differ. Strategic Management J. 14(4) 237-249.

Child, J., L. Chung, H. Davies. 2003. The performance of crossborder units in China: A test of natural selection, strategic choice and contingency theories. J. Internat. Bus. Stud. 34(3) 242-254.
Clark, E., A. Soulsby. 1995. Transforming former state enterprises in the Czech Republic. Organ. Stud. 16(2) 215-242.

Cyert, R. M., J. G. March. 1963. A Behavioral Theory of the Firm, 2nd ed. Prentice Hall, Englewood Cliffs, NJ.

D’Aunno, T., R. I. Sutton, R. H. Price. 1991. Isomorphism and external support in conflicting institutional environments: A study of drug abuse treatment units. Acad. Management J. 34(3) 636-661.

D'Aveni, R. A. 1994. Hypercompetition: Managing the Dynamics of Strategic Maneuvering. Free Press, New York.

Davis, J. P., K. M. Eisenhardt, C. B. Bingham. 2009. Optimal structure, market dynamism, and the strategy of simple rules. Admin. Sci. Quart 54(3) 413-452.

Deephouse, D. L. 1999. To be different, or to be the same? It's a question (and theory) of strategic balance. Strategic Management J. 20(2) 147-166.

Dess, G. G., R. B. Robinson Jr. 1984. Measuring organizational performance in the absence of objective measures: The case of the privately-held firm and conglomerate business unit. Strategic Management J. 5(3) 265-273.

Dill, W. R. 1958. Environments as an influence on managerial autonomy. Admin. Sci. Quart. 2(4) 409-443.

DiMaggio, P. J. 1991. Constructing an organizational field as a professional project: U.S. art museums, 1920-1940. W. W. Powell, P. J. DiMaggio, eds. The New Institutionalism in Organizational Analysis. University of Chicago Press, Chicago, 267-292.

DiMaggio, P. J., W. W. Powell. 1983. The iron cage revisited: Institutional isomorphism and collective rationality in organizational fields. Amer. Sociol. Rev. 48(2) 147-160.

Dobrev, S. D., G. R. Carroll. 2003. Size (and competition) among organizations: Modeling scale-based selection among automobile producers in four major countries, 1885-1981. Strategic Management J. 24(6) 541-558.

Donaldson, L. 1987. Strategy and structural adjustment to regain fit and performance: In defense of contingency theory. J. Management Stud. 24(1) 1-24.

Donaldson, L. 2001. The Contingency Theory of Organizations. Sage, Thousand Oaks, CA.

Donaldson, L. 2008a. Resolving the conflict between contingency and institutional theories of organizational design. R. M. Burton, B. H. Erikson, D. D. Håkonsson, T. Knudsen, C. C. Snow, eds. Designing Organizations: 21st Century Approaches. Springer, New York, 21-40.

Donaldson, L. 2008b. The conflict between contingency and institutional theories of organizational design. R. M. Burton, B. H. Erikson, D. D. Håkonsson, T. Knudsen, C. C. Snow, eds. Designing Organizations: 21st Century Approaches. Springer, New York, 3-20.

Drazin, R., A. H. Van de Ven. 1985. Alternative forms of fit in contingency theory. Admin. Sci. Quart. 30(4) 514-539.

Duncan, R. B. 1972. Characteristics of organizational environments and perceived environmental uncertainties. Admin. Sci. Quart. 17(3) 313-327.

Emery, F. E., E. Trist. 1965. The causal texture of organizational environments. Human Relations 18(1) 21-31.

Fines, C. H. 1998. Clockspeed: Winning Industry Control in the Age of Temporary Advantage. Perseus, Reading, MA.

Fornell, C., D. F. Larcker. 1981. Evaluating structural equation models with unobservable variables and measurement error. J. Marketing Res. 18(1) 39-50. 
Glick, W. H. 1985. Conceptualizing and measuring organizational and psychological climate: Pitfalls in multilevel research. Acad. Management Rev. 10(3) 601-616.

Greening, D. W., B. Gray. 1994. Testing a model of organizational response to social and political issues. Acad. Management J. 37(3) 467-498.

Greenwood, R., C. R. Hinings. 1996. Understanding radical organizational change: Bringing together the old and the new institutionalism. Acad. Management Rev. 21(4) 1022-1054.

Griliches, Z. 1957. Hybrid corn: An exploration in the economics of technological change. Econometrica 25(4) 501-522.

Gupta, P. P., M. W. Dirsmith, T. J. Fogarty. 1994. Coordination and control in a government agency-Contingency and institutional theory perspectives on GAO audits. Admin. Sci. Quart. 39(2) 264-284.

Hair, J. F., Jr., R. E. Anderson, R. L. Tatham, W. C. Black. 1998. Multivariate Data Analysis, 5th ed. Prentice Hall, Englewood Cliffs, NJ.

Hambrick, D. C. 1983. Some tests of the effectiveness and functional attributes of Miles and Snow's strategic types. Acad. Management J. 26(1) 5-26.

Haunschild, P. R., A. S. Miner. 1997. Modes of interorganizational imitation: The effects of outcome salience and uncertainty. Admin. Sci. Quart. 42(3) 472-500.

Heugens, P. M. A. R., M. W. Lander. 2009. Structure! Agency! (and other quarrels): A meta-analysis of institutional theories of organization. Acad. Management J. 52(1) 61-85.

Hickson, D. J., D. S. Pugh, D. C. Pheysey. 1969. Operations technology and organization structure: An empirical reappraisal. Admin. Sci. Quart. 14(3) 378-397.

Hill, T. 1983. Production/Operations Management: Text and Cases. Prentice Hall, New York.

Hitt, M. A., L. Bierman, K. Shimizu, R. Kochhar. 2001. Direct and moderating effects of human capital on strategy and performance in professional service firms: A resource-based perspective. Acad. Management J. 44(1) 13-28.

Hofer, C. W. 1975. Toward a contingency theory of business strategy. Acad. Management J. 18(4) 784-810.

Hofstede, G., B. Neuijen, D. D. Ohayv, G. Sanders. 1990. Measuring organizational cultures: A qualitative and quantitative study across twenty cases. Admin. Sci. Quart. 35(2) 286-316.

Hrebiniak, L. G., W. F. Joyce. 1985. Organizational adaptation: Strategic choice and environmental determinism. Admin. Sci. Quart. 30(3) 336-349.

James, L. R., R. G. Demaree, G. Wolf. 1993. $r_{w g}$ : An assessment of within-group interrater agreement. J. Appl. Psych. 78(2) 306-309.

Jaworski, B. J., A. K. Kohli. 1993. Market orientation: Antecedents and consequences. J. Marketing 57(3) 53-70.

Jones, A. P., L. A. Johnson, M. C. Butler, D. S. Main. 1983. Apples and oranges: An empirical comparison of commonly used indices of interrater agreement. Acad. Management J. 26(3) $507-519$

Kondra, A. Z., C. R. Hinings. 1998. Organizational diversity and change in institutional theory. Organ. Stud. 19(5) 743-767.

Kraatz, M. S., E. J. Zajac. 1996. Exploring the limits of the new institutionalism: The causes and consequences of illegitimate organizational change. Amer. Sociol. Rev. 61(5) 812-836.

Lawrence, P. R., J. W. Lorsch. 1967. Organization and Environment. Division of Research, Harvard Business School, Boston.
Lee, J., D. Miller. 1996. Strategy, environment and performance in two technological contexts: Contingency theory in Korea. Organ. Stud. 17(5) 729-750.

Levinthal, D. A. 1991. Organizational adaptation and environmental selection-Interrelated processes of change. Organ. Sci. 2(1) 140-145.

Levitt, B., J. G. March. 1988. Organizational learning. Annual Rev. Sociol. 14 319-338.

Lewin, A. Y., H. W. Volberda. 1999. Prolegomena on coevolution: A framework for research on strategy and new organizational forms. Organ. Sci. 10(5) 519-534.

Lindell, M. K., C. J. Brandt. 2000. Climate quality and climate consensus as mediators of the relationship between organizational antecedents and outcomes. J. Appl. Psych. 85(3) 331-348.

March, J. G. 1981. Footnotes to organizational change. Admin. Sci. Quart. 26(4) 563-577.

Meyer, J. W., B. Rowan. 1977. Institutionalized organizations: Formal structure as myth and ceremony. Amer. J. Sociol. 83(2) 340-363.

Mintzberg, H. 1979. The Structuring of Organizations. Prentice Hall, Englewood Cliffs, NJ.

Nadkarni, S., V. K. Narayanan. 2007. Strategic schemas, strategic flexibility, and firm performance: The moderating role of industry clockspeed. Strategic Management J. 28(3) 243-270.

Nunnally, J. 1967. Psychometric Theory. McGraw-Hill, New York.

Orru, M., N. W. Biggart, G. G. Hamilton. 1991. Organizational isomorphism in East Asia. W. W. Powell, P. J. DiMaggio, eds. The New Institutionalism in Organizational Analysis. University of Chicago Press, Chicago, 361-389.

Ouchi, W. G. 1979. A conceptual framework for the design of organizational control mechanisms. Management Sci. 25(9) 833-848.

Parker, S. C., A. van Witteloostuijn. 2010. A general framework for estimating multidimensional contingency fit. Organ. Sci. 21(2) $540-553$.

Pennings, J. M. 1987. Structural contingency theory: A multivariate test. Organ. Stud. 8(3) 223-240.

Perrow, C. 1967. A framework for the comparative analysis of organizations. Amer. Sociol. Rev. 32(2) 194-208.

Podsakoff, P. M., D. W. Organ. 1986. Self-reports in organizational research: Problems and prospects. J. Management 12(4) $531-556$.

Podsakoff, P. M., S. B. MacKenzie, J. Y. Lee, N. P. Podsakoff. 2003. Common method biases in behavioral research: A critical review of the literature and recommended remedies. J. Appl. Psych. 88(5) 879-903.

Porter, M. E. 1980. Competitive Strategy: Techniques for Analyzing Industries and Competitors. Free Press, New York.

Priem, R. L. 1994. Executive judgment, organizational congruence, and firm performance. Organ. Sci. 5(3) 421-437.

Pugh, D. S., D. J. Hickson, C. R. Hinings, K. M. Macdonald, C. Turner, T. Lupton. 1963. A conceptual scheme for organizational analysis. Admin. Sci. Quart. 8(3) 289-315.

Roth, K., A. J. Morrison. 1992. Business-level competitive strategy: A contingency link to internationalization. J. Management 18(3) 473-487.

Scott, W. R. 2001. Institutions and Organizations. Sage, Thousand Oaks, CA

Scott, W. R. 2003. Organizations: Rational, Natural, and Open Systems. Prentice Hall, Upper Saddle River, NJ. 
Siggelkow, N. 2001. Evolution toward fit. Admin. Sci. Quart. 47(1) $125-159$.

Smith, K. G., J. P. Guthrie, M.-J. Chen. 1989. Strategy, size and performance. Organ. Stud. 10(1) 63-81.

Thompson, J. D. 1967. Organizations in Action: Social Science Bases of Administrative Theory. McGraw-Hill, New York.

Tolbert, P. S., L. G. Zucker. 1983. Institutional sources of change in the formal structure of organizations: The diffusion of civil service reform, 1880-1935. Admin. Sci. Quart. 28(1) 22-39.

Tolbert, P. S., L. G. Zucker. 1996. The institutionalization of the institutional field. S. R. Clegg, C. Hardy, W. R. Nord, eds. Handbook of Organization Studies. Sage, London, 175-190.

Tosi, H. L., Jr., J. W. Slocum Jr. 1984. Contingency theory: Some suggested directions. J. Management 10(1) 9-26.

Van de Ven, A. H. 1979. Review of Organizations and Environments. Admin. Sci. Quart. 24(2) 320-326.

Van de Ven, A. H., R. Drazin. 1985. The concept of fit in contingency theory. B. M. Staw, L. L. Cummings, eds. Research in Organizational Behavior, Vol. 7. JAI Press, Greenwich, CT, 333-365.

Van de Ven, A. H., D. L. Ferry. 1980. Measuring and Assessing Organizations. John Wiley \& Sons, New York.

Venkatraman, N. 1989. Strategic orientation of business enterprises: The construct, dimensionality, and measurement. Management Sci. 35(8) 942-962.

Venkatraman, N., J. E. Prescott. 1990. Environment-strategy coalignment: An empirical test of its performance implications. Strategic Management J. 11(1) 1-23.

Volberda, H. W. 1996. Toward the flexible form: How to remain vital in hypercompetitive environments. Organ. Sci. 7(4) 359-374.

Volberda, H. W. 1998. Building the Flexible Firm: How to Remain Competitive. Oxford University Press, New York.

Volberda, H. W., A. Y. Lewin. 2003. Co-evolutionary dynamics within and between firms: From evolution to co-evolution. J. Management Stud. 40(8) 2111-2136.

Volberda, H. W., N. J. Foss, M. A. Lyles. 2010. Absorbing the concept of absorptive capacity: How to realize its potential in the organization field. Organ. Sci. 21(4) 931-951.

Von Bertalanffy, L. 1951. General system theory: A new approach to unity of science. Human Biol. 23(4) 303-361.

Washington, M., M. J. Ventresca. 2004. How organizations change: The role of institutional support mechanisms in the incorporation of higher education visibility strategies, 1874-1995. Organ. Sci. 15(1) 82-97.

Weick, K. E. 1979. The Social Psychology of Organizing, 2nd ed. Random House, New York.

Wicks, D. 2001. Institutionalized mindsets of invulnerability: Differentiated institutional fields and the antecedents of organizational crisis. Organ. Stud. 22(4) 659-692.

Williams, C. 2008. Comparing evolutionary and contingency theory approaches to organizational structure. R. M. Burton, B. H. Erikson, D. D. Håkonsson, T. Knudsen, C. C. Snow, eds.
Designing Organizations: 21st Century Approaches. Springer, New York, 41-56.

Woodward, J. 1965. Industrial Organization: Theory and Practice. Oxford University Press, London.

Zajac, E. J., M. S. Kraatz, R. K. F. Bresser. 2000. Modeling the dynamics of strategic fit: A normative approach to strategic change. Strategic Management J. 21(4) 429-453.

Zeithaml, V. A., P. R. Varadarajan, C. P. Zeithaml. 1988. The contingency approach: Its foundations and relevance to theory building and research in marketing. Eur. J. Marketing 22(7) 37-64.

Zucker, L. G. 1977. The role of institutionalization in cultural persistence. Amer. Sociol. Rev. 42(5) 726-743.

Zucker, L. G. 1987. Institutional theories of organization. Annual Rev. Sociol. 13 443-464.

Henk W. Volberda is a professor of strategic management and business policy and director of knowledge transfer at the Rotterdam School of Management, Erasmus University. He is scientific director of the top institute INSCOPE, member of the board of the Netherlands Center for Social Innovation, and vice president of the European Academy of Management. His research on strategic renewal, organizational flexibility, coevolution, and innovation has been published in many books and in a wide range of journals.

Niels van der Weerdt is an assistant professor in the Department of Strategic Management and Entrepreneurship at the Rotterdam School of Management, Erasmus University. His research focuses on the measurement and performance consequences of organizational flexibility and design choices. He received an M.Sc. in business administration and a Ph.D. in strategic management from Erasmus University Rotterdam.

Ernst Verwaal is a professor of international business and market strategy at the Queen's University Management School, Belfast. His research focuses on how firms develop competitive advantage in international markets using institutional structures, governance mechanisms, cooperative networks, and analytics-based strategic decision making. He received an M.Sc. in economics and business administration from the University of Amsterdam and a Ph.D. in international business studies from Leiden University.

Marten Stienstra is an assistant professor of strategic management at the Rotterdam School of Management, Erasmus University. He received his Ph.D. from the same institution. His research interests include organizational design and strategic renewal, with particular emphasis on the role of institutional issues in these processes.

Antonio J. Verdu is an associate professor of strategic management at Miguel Hernandez University. He received his Ph.D. from the University of Granada (Spain). He worked as a postdoc at the Rotterdam School of Management, Erasmus University. His research interests include strategic change, organizational adaptation, and business environment, with particular emphasis on the dynamics of fit. 